\title{
Research on Constructivism-based Collaborative Learning Mode
}

\author{
Jinbo Bai ${ }^{1}$, Hongbo Li ${ }^{2}$, Jianping Chen ${ }^{2}$ \\ ${ }^{1}$ Economics \& Management College, Zhaoqing University, Zhaoqing, China \\ ${ }^{2}$ School of Computer Science and Software, School of Big Data, Zhaoqing University, Zhaoqing, \\ China.
}

Keywords: Constructivism, Web2.0, Collaborative Learning, Mode.

\begin{abstract}
Aiming at the drawbacks that are found by analyzing online teaching at the present, we discuss the impact of concept and technology of Web2.0 on collaborative learning and knowledge construction. In order to improve the quality of online teaching and learning, a new collaborative learning mode is proposed based on constructivism theory and Web2.0 technology in this paper, and its characteristics is interpreted in detail. The mode includes some popular technologies, such as blog, wiki, tagging, and so on. With the further popularization of Internet and mobile Internet, the new mode will have an important and positive impact on online teaching, which is beneficial to learners by providing hierarchical online teaching resources, and training autonomous learning ability of learners in the long run.
\end{abstract}

\section{Introduction}

With the rapid and all-sided development of Internet and mobile Internet, the way of learning, living and working has been changed, and a new broad and more convenient channel of information accessing and teaching has been opened. The Web2.0 technology provides learners with a brand new idea and technology support for their knowledge construction. In order to improve the quality of online teaching and learning and the student's ability of knowledge construction, a novel learning mode based on constructivism will be put forward in this paper, which takes full advantage of Web2.0 and takes the collaborative learning as a means.

\section{Drawbacks of present online teaching}

Nowadays, online teaching has been a very common teaching method. However, we find some drawbacks of it through deep survey and study, and sum them up as follows.

(1) The content presentation of knowledge is emphasized, but the construction of knowledge is insufficient. In general, the present online teaching simply moves content from textbooks or blackboard to the Internet in a static style (such as documents). In essence it only turns printing material into electronic material, and lets the Internet substitute for teachers to imbue learners with knowledge. In this situation, the learning status of students is passive, and the traditional teaching mode has no fundamental change.

(2) Interaction between learners is lacking or none. In the process of traditional online teaching, each learning individual forms an autonomous system. The separation from each other results in the interesting lacking of the learners. Even if communications occur between some learners sometimes, mutual influence and inspiration, and mutual promotion are extremely limited. There are maybe a lot of impact factors, but the most important one is that the traditional online teaching didn't provide learners with a proper communicating tool. In a nutshell, collaborative learning mode has not been constructed.

(3) Resource sharing is very difficult. Nowadays web user is not only an online resource consumer, but also a content producer. However, the online resource produced by an ordinary user is unstructured and unorganized. In addition, because of the variety of resource types, such as text, images, video, 
audio, etc., even if there is some kind of tool to handle them the retrieving accurate ratio is still a big problem. The retrieving difficulty severely impedes resource sharing among learners.

(4) The constructive design of learning situation and environment is not enough. According to the constructivism theory, the learning situation and environment are vital to learners. However, due to the high cost of moving contexts, especially static contexts, in reality to Internet, the construction of online learning situation and environment are very difficult.

(5) Shortage of incentive mechanism leads to the vast majority of learners missing online learning interests. In accordance with Maslow's hierarchy of needs theory (as shown in the figure 1), after the needs of physiological, safety and love/belonging been satisfied or realized, the esteem need of an individual should be satisfied or realized. In this phase, learners crave for respect from others. Once the desires are confirmed only illusions, most of the learners lost interests and motivations to learn more. Meanwhile many learners feel that their self-esteems are invaded gravely.

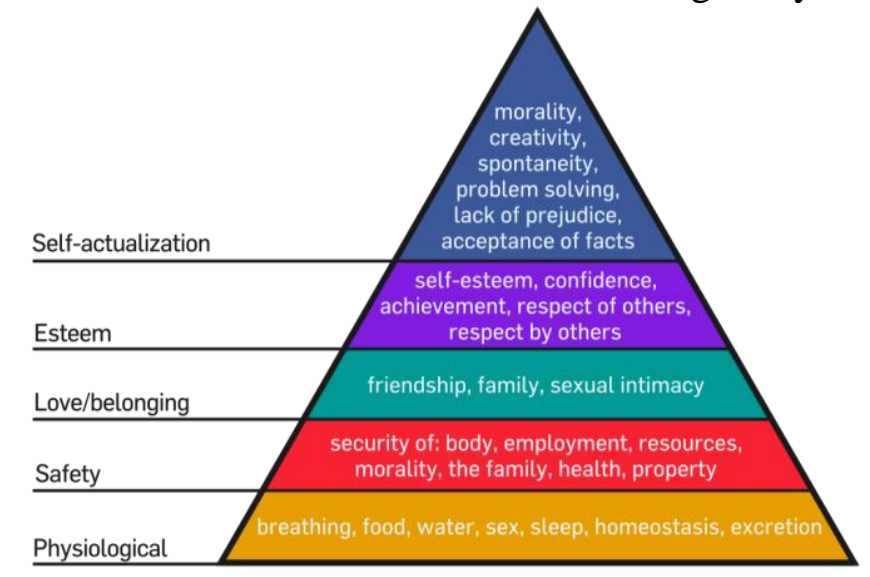

Figure 1. An interpretation of Maslow's hierarchy of needs [1].

(6) Proper integrating theories and approaches of modern teaching tools and technologies are needed. Though there are many study of modern teaching tools and technologies, such as Internet, Web2.0, constructivism, collaborative learning, and so on, they are scattered and not integrated. Lack integration of modern teaching tools and technologies in the relative studies leads to the aforementioned problems. So in this paper we propose a constructivism-based collaborative learning mode from the integrating perspective of modern teaching tools and technologies.

\section{Constructivism, collaborative learning and web2.0}

\subsection{Constructivism}

There are many "flavors" of constructivism, but one prominent theorist known for his constructivist views is Jean Piaget, who focused on how humans make meaning in relation to the interaction between their experiences and their ideas [2]. The constructivism learning theory emphasizes that learner should be put at the central position and be the active knowledge constructor in the learning process, meanwhile teacher is only a guider, an instructor and an auxiliary at the beginning phase [3-4]. Meanwhile the constructivism learning theory further emphasizes that all kinds of interactions between learner and external environment has an utmost importance [5-7].

\subsection{Collaborative Learning}

The Wikipedia profiles collaborative learning as follows: It is a situation in which two or more people learn or attempt to learn something together [8-9]. Unlike individual learning, people engaged in collaborative learning capitalize on one another's resources and skills (asking one another for information, evaluating one another's ideas, monitoring one another's work, etc.) [8, 10-11]. Collaborative learning activities can include collaborative writing, group projects, joint problem solving, debates, study teams, and other activities [8].1 


\subsection{Web2.0}

The popular term, Web2.0 (sometimes spelled as Web 2.0), refers to World Wide Web websites that emphasize user-generated content, usability (ease of use, even by non-experts), and interoperability (this means that a website can work well with other products, systems, and devices) for end users [12]. Web2.0 emphasizes the end user's central position and participation, openness, sharing and interaction, individuation, sociality and creativity. These features of Web2.0 provide the online learning with a strong support.

\section{Constructivism-based collaborative learning mode}

Based on studying and discussing on constructivism, collaborative learning and Web2.0 Technology, we propose a learning mode to improve online learning effect. The main concepts of the new mode are as follows.

Weakening the teacher's central position in learning situation setting. Teachers only provide learners with learning situation outlines. Learners can abide by it and fill it up in details, can change it, and even can overthrow it according to the most learners' wishes.

Providing promoting communication and interaction tools being supported by Web2.0, such as chat room, forum, blog, and so on. In order to improve complementary abilities, in the real application context we can select more than one Web2.0 tool.

According to the approach proposed in [13] tag every online resource. This approach belongs to folksonomy technology supported by Web2.0. A folksonomy is a system in which users apply public tags to online items, typically to aid themselves or others in re-finding those items later. Though folksonomy is a proven technology, it has two main insurmountable flaws: cold boot and inaccurate tagging [13]. Through inheriting the ideas in [14], the flaws have been weakened greatly by the approach in [13].

Creating a committee that can reflect the majority learner's aspiration. It is recommended that the committee should be a temporary agency. A temporary agency has several advantages. First, aiming at a new task the "experts" elected by all learners can be collected in the committee, so it can express the common aspiration more proper. Second, the committee can make a decision of setting or changing a teaching situation, and assign "experts" to complete it with a comparatively higher efficiency and lower cost.

Quantify every item of every task, and assigning the score to the learner who has finished an item of a task. The marks can be decided by the committee, and the assignment can be done by the system automatically.

There are five parts of the mode: active knowledge constructors, communication and interaction tools, tagging system, a temporary committee and an incentive mechanism. Learners becoming active knowledge constructors mean that the learning center transfers from teachers to learners. The application of tools and tagging system supported by Web2.0 technology makes the information interchange, interaction and resource sharing easy, and the solving of puzzles timely. A temporary committee guarantees the mode system working regularly, and the resources are utilized properly. The incentive mechanism enables learners to maintain continuous learning interest.

\section{Summary}

Based on constructivism and making full use of the collaborative learning and Web2.0 technology, we propose a new online learning mode. It has several characteristics as follows. Firstly, the mode reflects collective consciousness, has self-learning and evolutionary abilities. Secondly, the mode is convenient to learner's information interchange, interaction and resource sharing. Thirdly, the mode makes for the keeping of learner's interest. Fourthly, the mode makes learners become active knowledge constructors. 


\section{Acknowledgements}

This research was supported by the Research Project of Education Development Research Institute of Zhaoqing City (No. ZQJYY2016043, ZQJYY2017002), the Research Project of 2016 Practice Teaching Reform of Zhaoqing University (No. SJJX201601), Guangdong Higher Education Institute Laboratory Management Professional Committee Fund Project (No. GDJ2016027).

The corresponding authors are Hongbo Li (Email: islhb@126.com) and Jianping Chen (Email: 40436741@qq.com).

\section{References}

[1] https://en.wikipedia.org/wiki/Abraham_Maslow

[2] https://en.wikipedia.org/wiki/Constructivism_(philosophy_of_education)

[3] Ertmer P A, Newby T J. 2013. "Behaviorism, Cognitivism, Constructivism: Comparing Critical Features from an Instructional Design Perspective," Performance Improvement Quarterly, 26(2): 43-71.

[4] Vanderstraeten R. 2015. “The Forgotten Temporal Dimension of Luhmann's Constructivism," Constructivist Foundations, 10(2): 212-214.

[5] Hall H, Griffiths D, McKenna L. 2013. "From Darwin to Donstructivism: The Evolution of Grounded Theory," Nurse researcher, 20(3): 17-21.

[6] Gouanvic J M. 2014. "A Model of Structuralist Constructivism in Translation Studies," Crosscultural Transgressions: 93-102.

[7] Doolittle P E. 2014. "Complex Constructivism: A Theoretical Model of Complexity and Cognition," International Journal of teaching and learning in higher education, 26(3): 485-498.

[8] https://en.wikipedia.org/wiki/Collaborative_learning

[9] Dillenbourg, P. 1999. "Collaborative Learning: Cognitive and Computational Approaches," Advances in Learning and Instruction Series. New York, NY: Elsevier Science, Inc.

[10]Chiu, M. M. 2000. "Group Problem Solving Processes: Social Interactions and Individual Actions," Theory of Social Behavior, 30, 1, 27-50.600-631.

[11]Chiu, M. M. 2008. "Flowing Toward Correct Contributions During Groups' Mathematics Problem Solving: A Statistical Discourse Analysis," Journal of the Learning Sciences, 17 (3), 415 $-463$.

[12] https://en.wikipedia.org/wiki/Web_2.0

[13]Bai J B, Li H B, Sun X, et al. 2017. "Summary Extract Approach of Heterogeneous Multimedia Documents Based on Folksonomy with Incentive and Quality Assurance Mechanisms," in International Conference on Economics, Management Engineering and Marketing (EMEM 2017): 198-205.

[14]Bai J B, Zhao J L, Li H B. 2011. "Multimedia Retrieval Based on Tagging Technology and Communities Performance Evaluation,” Journal of Intelligence, 30(9): 155-159. 